\title{
Myocardial infarction after cardiac surgery: When to intervene?
}

Johny Nicolas, MD, ${ }^{\mathrm{a}}$ Kevin Soriano, MD, ${ }^{\mathrm{a}}$ Benjamin Salter, DO, ${ }^{\mathrm{b}}$ Caroline R. Gross, MD, ${ }^{\mathrm{b}}$ Mehdi Oloomi, MD, ${ }^{\mathrm{a}}$ and George Dangas, $\mathrm{MD}, \mathrm{PhD}^{\mathrm{a}}$

Feature Editor's Introduction-Diagnosing myocardial infarction following cardiac surgery can be challenging. Hospitals have different activation protocols when myocardial ischemia is suspected, which ultimately aim to preserve the myocardium from further cellular loss by timely restoration of the coronary blood flow. Individual signs such as physical examination, biomarkers, and electrocardiographic changes are rather nonspecific and common after cardiac surgery and often perioperative teams are unsure about the appropriate management. This Invited Expert Opinion article by Dangas and colleagues explores the underlying etiologies, clinical evaluation, and management strategies of postoperative myocardial infarction after cardiac surgery. The authors focus on 2 specific etiologies for postoperative myocardial infarction (coronary artery bypass graft failure and injury during valvular surgery), and they center their in-depth discussion on the assessment and management of these serious adverse events.

\section{Mariya Geube, MD}

Over the past decades, cardiac surgery (CS) has undergone a rapid and remarkable development that significantly decreased complications and improved surgical outcomes. Nonetheless, myocardial infarction (MI) remains an important postoperative complication. The actual incidence of postoperative MI varies across studies $(2 \%-10 \%)$ and is highly dependent on the definition used (ie, Third Universal Definition of MI, Fourth Universal Definition of MI, Society for Cardiovascular Angiography and Intervention definition, etc). ${ }^{1,2}$

Whereas the criteria for nonprocedure-related MI are well defined, reaching a consensus on a single definition for procedure-related MI has been challenging. ${ }^{2}$ As patients are rarely capable of reporting the classic ischemic

From the ${ }^{\mathrm{a}}$ Department of Cardiology, Zena and Michael A. Wiener Cardiovascular Institute, and ${ }^{\mathrm{b}}$ Department of Anesthesiology, Icahn School of Medicine at Mount Sinai, New York, NY

Received for publication March 7, 2021; revisions received July 5, 2021; accepted for publication Aug 1, 2021; available ahead of print Sept 6, 2021.

Address for reprints: George Dangas, MD, PhD, The Zena and Michael A. Wiener Cardiovascular Institute, Icahn School of Medicine at Mount Sinai, One Gustave

L. Levy Place, Box 1030, New York, NY 10029-6574 (E-mail: gdangas@crf.org).

J Thorac Cardiovasc Surg 2023;165:1195-201

$0022-5223 / \$ 36.00$

Copyright (c) 2021 by The American Association for Thoracic Surgery

https://doi.org/10.1016/j.jtcvs.2021.08.074

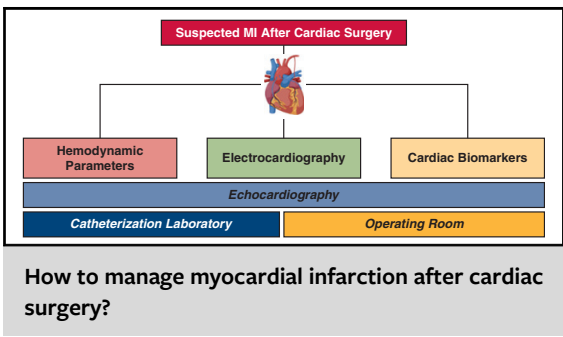

CENTRAL MESSAGE

Suspicion of myocardial ischemia

right after cardiac surgery re-

quires prompt clinical evaluation

and transfer to the catheteriza-

tion laboratory or to the oper-

ating room, if deemed necessary.

See Commentaries on pages 1202 and 1203.

symptoms shortly after CS, clinicians in the intensive care (ICU) and step-down units rely mostly on diagnostic tests to establish the diagnosis of MI. In addition, high-level evidence-driven guidance is lacking, as most findings are based on observational studies and expert consensus documents (rather than any randomized study). Therefore, the management of postoperative MI in the context of CS remains a topic of ongoing debate.

Hereafter, we aim to provide guidance on the management of MI in the setting of CS, mainly after coronary artery bypass and heart valve surgeries. Although the etiologies of post-CS MI are different in the aforementioned operations, the overall management approach is rather similar.

\section{UNDERLYING ETIOLOGIES}

Various factors can lead to myocardial injury after CS. Many of them are related to the extent of myocardial tissue damage, potential ischemic injury, and the technical aspects of the surgery inclusive of any related cardioplegia applied. ${ }^{3}$ In this review, we focus on 2 common etiologies of MI after coronary and valvular surgeries.

\section{Graft Failure After Bypass Surgery}

Graft dysfunction is a complex phenomenon that may rarely occur early in the postoperative period. Graft 
harvesting approaches, vessel selection (ie, venous vs arterial), myocardial-preservation solutions (ie, normal saline, heparinized blood, crystalloid solution, etc.), and anastomosis techniques all play a role in determining the surgical outcome. Graft failure is usually due to thrombotic occlusion, anastomotic stenosis, bypass graft kinking, overstretching, or vasoconstriction. Radial artery conduits are particularly prone to spasm due to adrenergic receptors' dominance in the underlying vascular smooth muscle and decreased endothelial nitric oxide synthase expression. Moreover, perioperative vasopressor use may extend several days in the ICU/step-down unit and may affect graft flow after coronary artery bypass graft (CABG) surgery. Another essential factor to consider is the surgical approach used, such as on-pump or off-pump coronary artery bypass. Several studies reveal greater graft patency and more complete revascularization after on-pump coronary artery bypass. ${ }^{4}$ However, surgeon experience, conduit selection, and postoperative anticoagulation allow safe off-pump coronary artery bypass in selected patients. ${ }^{5,6}$

\section{Coronary Artery Injury During Valvular Surgery}

Coronary stenosis/occlusion resulting in acute ischemia is a rare but well-reported complication of valvular surgery. ${ }^{7}$ The injury mechanisms are numerous (ie, distortion, twisting, or laceration of the coronary artery), but most are related to surgical stitch placement. For example, stenosis of the left circumflex artery, especially in left-dominant coronary artery circulation, occurs during mitral valve repair due to its proximity to the mitral annulus where the suture is fixed. The annulus may be $5 \mathrm{~mm}$ or less from the left circumflex artery (Figure 1) and can frequently be visualized by advanced intraoperative echocardiography. In this setting, ischemia may lead to significant hemodynamic compromise. Similarly, the right coronary artery can be injured or occluded during tricuspid valve repair with both suture and ring annuloplasty. The right coronary artery closely approximates the tricuspid annulus, especially in the cavotricuspid isthmus in the lower right atrium (Figure 2). A thorough understanding of the anatomic relationship between coronary and valvular anatomy is critical to minimizing these types of complications during CS.

An uncommon but important cause of post-CS MI is coronary ostial stenosis following a combined valve-graft replacement of the aortic root (also known as the Bentall procedure). Extrinsic compression or distortion of the replanted coronary neo-ostium may result in vessel occlusion and subsequent MI in the early postoperative period. Cabrol grafts to the proximal right coronary artery and the left main arteries is another surgical option that allows coronary perfusion from a very high plane relative to the aortic valve, thereby facilitating future valve procedures but also avoiding stretching/kinking of the proximal native coronary arteries. $^{9}$

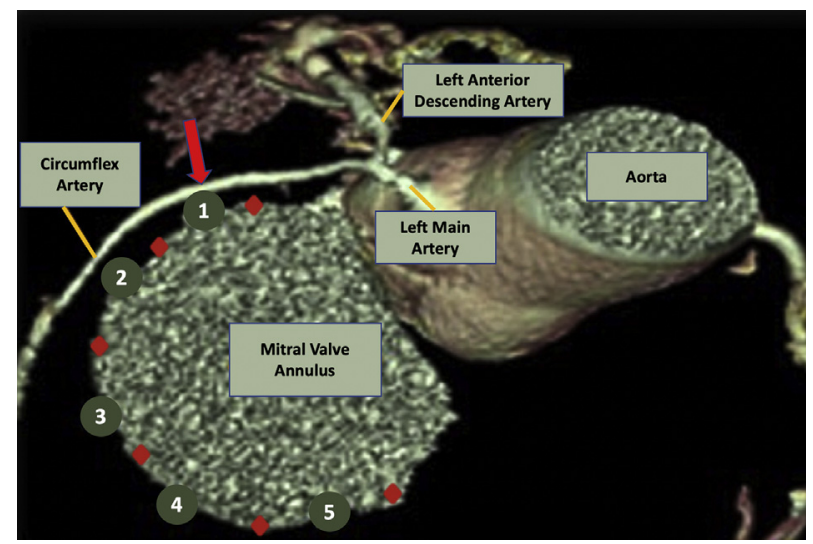

FIGURE 1. Coronary computed tomography angiography showcasing the proximity of the circumflex artery to the mitral valve annulus. Five zones (numbered from 1 to 5 ) of varying distances between the mitral valve annulus and the circumflex artery are shown in the figure. These zones are lying between 6 points (red squares). The circumflex artery is closest to the mitral valve annulus in zone 1; the red arrow points to the most vulnerable portion of the circumflex artery regarding potential entrapment by a suture. Figure adapted from Caruso V, Shah U, Sabry H, Birdi I. Mitral valve annulus and circumflex artery: in vivo study of anatomical zones. $J$ Thorac Cardiovasc Surg Tech. 2020;4:122-9.

\section{CLINICAL EVALUATION}

\section{Signs and Symptoms of Myocardial Ischemia}

Common ischemic symptoms, such as angina and shortness of breath, are not typically evaluable in intubated and sedated patients in ICU. A thorough evaluation of the patient's hemodynamic status should serve as a starting point when myocardial ischemia is suspected. Whenever possible, invasive hemodynamic monitoring with a pulmonary artery catheter should be considered, as increased filling pressures may be highly suggestive of MI. Other Swan-Ganz catheter (Edwards Lifesciences, Irvine, Calif)-derived data, such as cardiac output measurement, may also indicate the loss of viable myocardium and impairment in global cardiac function. However, all findings should be interpreted with caution, given the many coexisting postoperative conditions. For example, persistent hypotension requiring vasopressors is common following CS due to vasoplegia induced by prolonged cardiopulmonary bypass or cardiogenic shock and exacerbated by reduced preload or anesthetic medications. Similarly, elevated lactate levels in the ICU are common and represent an oxygen supply-consumption mismatch or impaired lactate clearance. However, this may be secondary to several postoperative etiologies (ie, hypoxemia, hyperglycolysis, hypovolemia, anemia, and liver injury) and not specific for coronary ischemia. ${ }^{10}$

\section{Cardiac Troponin (cTn) Levels}

Cardiac biomarkers play an essential role in detecting myocardial injury and have become critical in diagnosing 


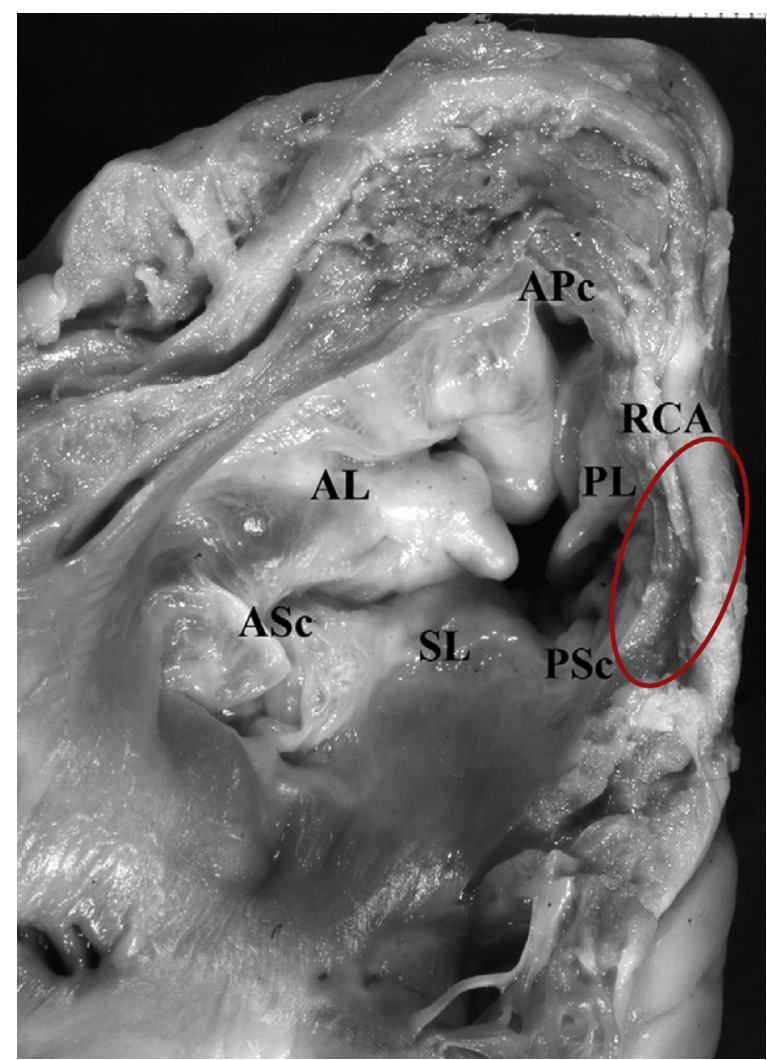

FIGURE 2. Tricuspid valve annulus and the right coronary artery $(R C A)$. The encircled area (in red) represents the region in which the right coronary artery is closest to the tricuspid annulus. $A P c$, Anteroposterior commissure; $A L$, anterior leaflet; $P L$, posterior leaflet; $A S c$, anteroseptal commissure; $S L$, septal leaflet; $P S c$, posteroseptal commissure. Figure adapted from Calafiore AM, Iacò AL, Bartoloni G, Di Mauro M. Right coronary occlusion during tricuspid band annuloplasty. $J$ Thorac Cardiovasc Surg. 2009;138:1443-4

MI. However, elevation in cTn levels is a common laboratory finding after cardiac surgery due to direct injury to the myocardium. As a result, identifying clinically significant increases in cTn that necessitate further investigation remains challenging.

According to the Fourth Universal Definition of MI, type 5 MI (also known as CABG-related MI) is defined as a cTn level increase of at least 10 times the 99th percentile upper reference limit in patients with normal baseline cTn values. ${ }^{2}$ In those with elevated baseline cTn and in whom cTn levels are stable or decreasing, the postprocedure cTn must increase by at least $20 \%$. However, the absolute postprocedural value still must be more than 10 times the 99th percentile upper reference limit. Creatine kinase isoenzyme makes a steeper upstroke/decline over 24 hours (than the several days of the cTn curve) and therefore easier to assess a subsequent re-elevation.

As no cTn cut-off values specific for valvular surgery have been established, the aforementioned mentioned values could be taken as reference when evaluating such patients. ${ }^{11}$ Whenever the aforementioned conditions are met, electrocardiogram (ECG) and noninvasive imaging should be used in parallel to increase the sensitivity and specificity for the diagnosis of MI.

Prolonged isolated elevation of cardiac biomarkers, unaccompanied by electrocardiographic or imaging findings, indicates procedure-related myocardial injury (ie, cardioplegia and reperfusion injury) that is typically not amenable to invasive management. ${ }^{1}$ Therefore, additional diagnostic testing is of limited value when the patient is in stable condition.

\section{Postoperative Electrocardiographic Findings}

All patients undergoing CS usually have a baseline ECG followed by serial postoperative ECG tracings. While ECG changes following CS are frequent and may be associated with postoperative ischemia, they are often nonspecific and benign. ST-segment and T-wave changes are common after CS because of pericardial and epicardial injury and thus are nonspecific indicators of MI postoperatively. However, specific ECG patterns, such as ST-segment elevation with reciprocal ST-depression, represent more reliable indicators of ischemia that require further noninvasive investigation (ie, cardiac biomarkers and echocardiography) before transferring the patient to the catheterization laboratory or back to the operating room. ${ }^{2}$ In contrast, development of new pathologic Q waves coupled with a significant rise in cardiac biomarkers (not necessarily more than 10 times the 99th percentile upper reference limit) represent the strongest evidence that prompts angiographic evaluation to rule out graft or native coronary artery occlusion. ${ }^{2}$ The appearance of a new persistent left bundle branch block (LBBB) on ECG is another strong marker of an ischemic event. However, in the setting of valvular surgery, we recommend the interpretation of this finding with caution, as LBBB commonly develops after valve replacement surgery. ${ }^{12}$

Ventricular arrhythmias following CS most often are due to metabolic and electrolyte abnormalities, catecholaminergic medications, reperfusion injury, scar tissue, and perioperative MI. In the setting of ventricular tachycardia/ ventricular fibrillation, the priority is urgent resuscitation, including defibrillation and correction of reversible causes of arrhythmia (ie, hyperkalemia, hypomagnesemia, and acidosis). The gravity of all the aforementioned findings increases when hemodynamic instability and elevated lactate level coexist.

\section{Echocardiography: Detection of Regional Ischemia}

Echocardiography is a powerful tool that enables the evaluation of ventricular and valvular function and the detection of myocardial dysfunction caused by regional or global ischemia. It is usually performed when results from 
biomarker testing and ECG are inconclusive, a common occurrence in postoperative MI cases. Regional wall motion abnormalities can be detected on echocardiography with direct correlation to the acute coronary occlusion territory. They depict decreases in amplitude and rate of myocardial contractility, as well as myocardial thickening and local remodeling. Nonetheless, regional wall motion abnormalities alone do not necessarily indicate acute ischemia, as they can be due to previous infarction, myocarditis, LBBB, or cardiomyopathy. They can also be related to ventricular pacing, inflammation, stunning, or hibernation post-CS. ${ }^{1}$ To localize and quantify the extent of an infarct, contrast echocardiography is recommended as it enhances visualization of all myocardial segments perfused by different native coronary arteries or bypass grafts. ${ }^{13}$ Notwithstanding, echocardiographic findings of global biventricular dysfunction, with or without regional variation, may be detected. Such observations may occur in the setting of a single or multiple graft failure to large coronary artery territories. In addition, they can be attributed to cardioplegia and other cardiac surgery-related physiologic changes that are not related to graft or native artery occlusion.

\section{MANAGEMENT STRATEGIES AND KEY ISSUES}

While the decision to intervene is under evaluation among the surgical and ICU teams, maintenance of the hemodynamic status and vital signs is of utmost importance. In patients with suspected postoperative ischemia, myocardial oxygen delivery should be optimized by increasing supply and decreasing demand. Although supplemental oxygen may not reduce mortality in patients without hypoxemia, oxygen should be supplied to preserve a greater than $90 \%$ saturation. Coronary perfusion pressure is maintained with vasopressors ahead of any consideration for ventricular unloading with any support device; tachycardia is minimized by avoiding sympathetic stimulation and providing appropriate analgesia.

\section{Watchful Waiting, Angiography, or Reoperation?}

Review of hemodynamic data, ECG findings, and bedside echocardiography should be done to rule out nonischemic causes of hemodynamic instability before considering percutaneous or surgical intervention (Figure 3). In absence of strong evidence from diagnostic tests besides cTn increases, watchful waiting with repeated testing (ie, serial measures of cardiac biomarkers and re-evaluation with electrocardiography and echocardiography) is preferred whenever the patient shows significant improvement in hemodynamic parameters. Conversely, when the suspicion for MI is high based on all the aforementioned intertwined factors, 2 main management options are possible: transfer to the operating room for surgical re-exploration without a clear diagnosis or transfer to the catheterization laboratory for further diagnostic workup with coronary angiography.
The former is mandatory for hemorrhagic emergencies and when a patient is in severe hemodynamic compromise despite all measures. Whenever the hemodynamic status permits, transfer to the catheterization is warranted. Coronary angiography is the gold standard for diagnosing postoperative MI (whether due to graft failure or coronary artery injury during valvular surgery), as it enables prompt implementation of optimal corrective measures that limit the extent of myocardial injury. While echocardiography can be performed at the bedside, angiography requires transfer to the cardiac catheterization laboratory, which may be difficult or dangerous in critically ill patients. In addition, the risk of contrast-associated nephropathy must be weighed against the benefits the procedure. ${ }^{14}$

\section{Percutaneous or Surgical Intervention?}

Following coronary angiography, most patients with an indication for repeat revascularization undergo percutaneous coronary intervention (PCI) with stenting. ${ }^{15}$ Besides the logistical reasons (ie, it is faster to perform percutaneous revascularization while the patient is already in the catheterization laboratory), repeat CS is not optimal, since many patients who develop postoperative MI are very high-risk candidates for immediate repeat CS. Long-term prognosis after such dramatic complication is guarded regardless of the treatment approaches. ${ }^{16}$

In case of graft failure, revascularization with PCI should be first considered in native vessels supplying ischemic myocardial tissue rather than in the occluded grafts. ${ }^{17}$ When coronary injury after valvular surgery is suspected postoperatively, PCI can be a valid option if arterial kinking is noted on coronary angiography. Conversely, in case of coronary artery occlusion due to total extrinsic obstruction, emergent reoperation should be preferred. In case of the Bentall procedure, ischemia can be managed with immediate surgical reintervention to identify the mechanical obstruction and reposition the coronary button or bypass grafting. Shared decision-making involving intensivists, cardiac surgeons, and interventional cardiologists is of paramount importance in all the aforementioned evaluations and decisions.

\section{Management of Antithrombotic Therapy}

Antithrombotic therapy may be initiated early after CS if the bleeding risk is deemed acceptable by the medical team. Assessment of the bleeding risk is performed on individual basis while accounting for various baseline risk factors: old age, low body mass index, active bleeding (ie, primarily through the chest tubes or in the pericardium), previous major bleeding, large volumes of intraoperative salvaged cells transfused, multiple coronary anastomoses, severe hepatic failure (international normalized ratio $>1.5$ ), severe renal failure (creatinine clearance $<30 \mathrm{~mL} / \mathrm{min}$ ), thrombocytopenia, and uncontrolled systemic hypertension. ${ }^{18}$ The 


\section{Suspected MI After Cardiac Surgery}

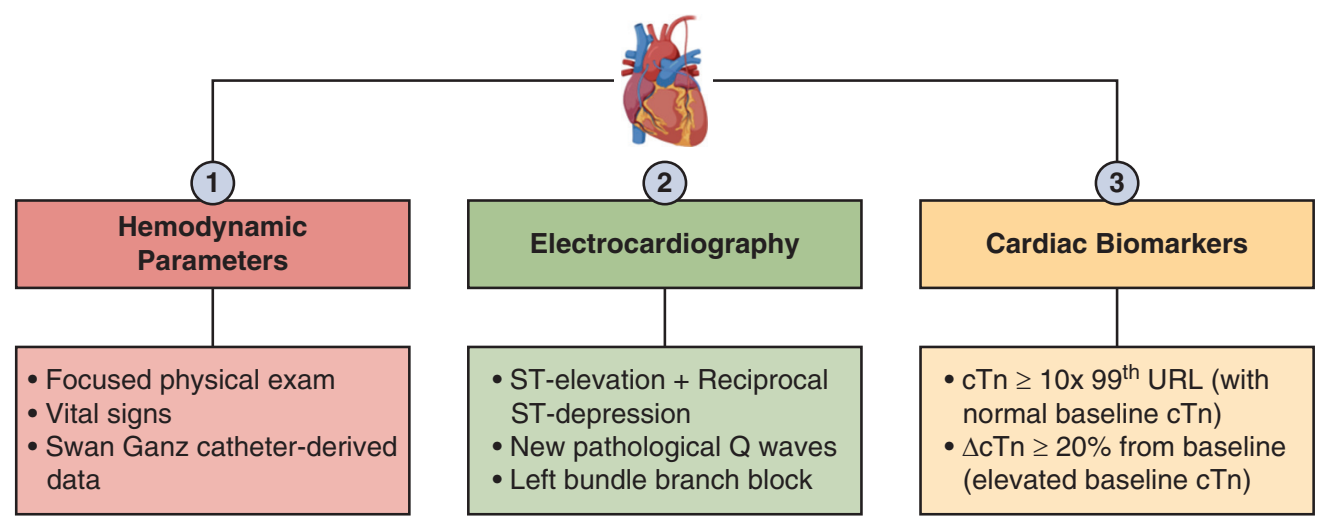

Stabilize/Maintain Hemodynamic Status

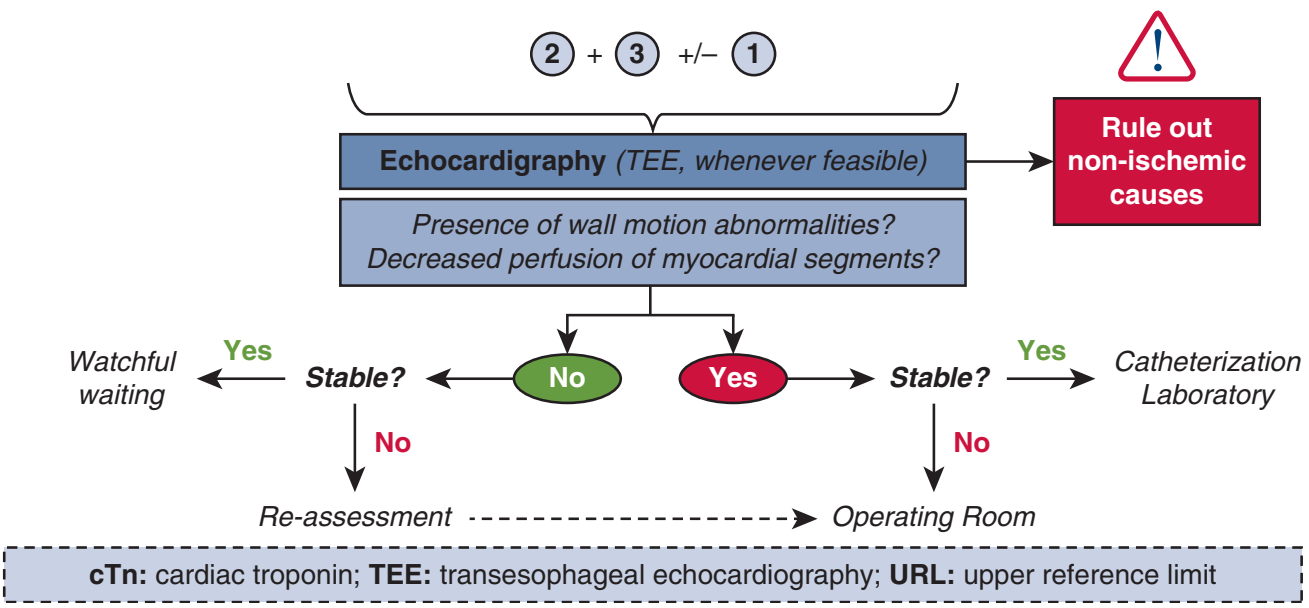

FIGURE 3. Algorithm for the management of suspected myocardial infarction $(M I)$ after cardiac surgery. Suspicion of MI after cardiac surgery requires assessment of hemodynamic parameters, electrocardiographic findings, and cardiac biomarkers. Whenever 1 or more of these tests reveals significant results, echocardiography is warranted. If noninvasive imaging suggests ischemic changes, the patient must be transferred to the catheterization laboratory for further diagnostic evaluation and revascularization (if deemed necessary). In case the patient is hemodynamically unstable, transfer to the operating room is recommended. Conversely, if the echocardiographic findings do not suggest ischemia and the patient is in a stable condition, watchful waiting with close monitoring is preferred.

optimal antithrombotic strategy after CS is beyond the scope of this paper; nonetheless, the entire team of ICU, surgery, and cardiology doctors should have a detailed understanding of the key options available (Table 1) to be able to select the most beneficial and flexible strategy in the very tenuous period early post-CS. To summarize, oral antiplatelet therapy consisting of aspirin with or without a $\mathrm{P}_{2} \mathrm{Y}_{12}$ inhibitor (clopidogrel, prasugrel, or ticagrelor) is recommended after CABG surgery, yet patients may not be able to swallow or absorb them early post-CS. In contrast, bridging with heparin while vitamin $\mathrm{K}$ antagonist therapy is being initiated is typically recommended after valvular surgery (again with few days delay, as mentioned previously). The time of initiation of antithrombotic therapy and the type of antithrombotic agents used influence the decision on whether to intervene and the type of intervention (surgical vs percutaneous). If the antithrombotic therapy has been initiated and the likelihood of an ischemic event is high, coronary angiography followed by PCI may be preferred over surgery to avoid lethal bleeding complications. In certain circumstances, such as ischemia due to mechanical obstruction after valvular procedure, surgical intervention may be the only option, and the ischemic risks outweigh the bleeding risks. In contrast, when no antithrombotic agent has been administered, aspirin may be given if the patient is at low bleeding risk. Other agents, such as $\mathrm{P}_{2} \mathrm{Y}_{12}$ inhibitors and heparin, should be avoided until a clear diagnosis is established. An intravenous $\mathrm{P}^{2} \mathrm{Y}_{12}$ inhibitor infusion may allow early reversal in case of hemorrhage.

Gastrointestinal complications after CS are not uncommon and narrow the options for oral drug administration. ${ }^{19}$ 
TABLE 1. Pharmacologic and clinical considerations of commonly used antithrombotic agents

\begin{tabular}{|c|c|c|c|c|c|c|c|}
\hline & Route & Mechanism of action & Time to onset & Half-life & $\begin{array}{c}\text { Activity } \\
\text { delayed in } \\
\text { MI/shock }\end{array}$ & $\begin{array}{c}\text { Time to } \\
\text { effect reversal }\end{array}$ & $\begin{array}{c}\text { Reversible } \\
\text { antithrombotic } \\
\text { activity? }\end{array}$ \\
\hline Aspirin & Oral & $\begin{array}{l}\text { Platelet COX-1 } \\
\text { enzyme inhibitor }\end{array}$ & $\begin{array}{l}20 \text { min } \\
\quad \text { (when chewed) }\end{array}$ & $\begin{array}{l}20 \text { min (3-10 } \\
\text { hours-dose- } \\
\text { dependent } \\
\text { for active } \\
\text { metabolite) }\end{array}$ & Yes & $4 \mathrm{~d}$ & Yes \\
\hline Clopidogrel & Oral & $\begin{array}{l}\text { Platelet } \mathrm{P} 2 \mathrm{Y} 12 \\
\text { receptor inhibitor }\end{array}$ & $2 \mathrm{~h}$ & $30 \min ^{*}$ & Yes & $5 \mathrm{~d}$ & Yes \\
\hline Ticagrelor & Oral & $\begin{array}{l}\text { Platelet } \mathrm{P} 2 \mathrm{Y} 12 \\
\text { receptor inhibitor }\end{array}$ & $30 \mathrm{~min}-1 \mathrm{~h}$ & $9 \mathrm{~h}^{*}$ & Yes & $4-5 d$ & No \\
\hline Prasugrel & Oral & $\begin{array}{l}\text { Platelet } \mathrm{P} 2 \mathrm{Y} 12 \\
\text { receptor inhibitor }\end{array}$ & $30 \mathrm{~min}$ & $7 \mathrm{~h}^{*}$ & Yes & $5-9 d$ & Yes \\
\hline Cangrelor & Intravenous & $\begin{array}{l}\text { Platelet } \mathrm{P} 2 \mathrm{Y} 12 \\
\text { receptor inhibitor }\end{array}$ & $2 \mathrm{~min}$ & $3-6 \mathrm{~min}$ & No & $30 \mathrm{~min}-1$ hour & $\mathrm{N} / \mathrm{A} \dagger$ \\
\hline Eptifibatide & Intravenous & $\begin{array}{l}\text { Platelet GP IIb/IIIa } \\
\text { receptor inhibitor }\end{array}$ & $<1 \mathrm{~h}$ & $2.5 \mathrm{~h}$ & No & $3-4 \mathrm{~h}$ & No \\
\hline Tirofiban & Intravenous & $\begin{array}{l}\text { Platelet GP IIb/IIIa } \\
\text { receptor inhibitor }\end{array}$ & $30 \min$ & $2.5 \mathrm{~h}$ & No & $4-8 \mathrm{~h}$ & No \\
\hline $\begin{array}{c}\text { Unfractionated } \\
\text { heparin } \ddagger\end{array}$ & Intravenous & $\begin{array}{l}\text { Blocks thrombin } \\
\text { generation and } \\
\text { activity }\end{array}$ & $2-4 \mathrm{~h} \ddagger$ & $30 \mathrm{~min}-2 \mathrm{~h} \ddagger$ & $\begin{array}{l}\text { No (inactive } \\
\text { against } \\
\text { clot-bound } \\
\text { thrombin) }\end{array}$ & $2-4 \mathrm{~h} \ddagger$ & Yes \\
\hline Bivalirudin & Intravenous & Direct thrombin inhibitor & Immediate & $30 \min$ & No & $1.5 \mathrm{~h}$ & No \\
\hline
\end{tabular}

Indeed, anticoagulant and antiplatelet agents in these patients must be given intraoperatively in the intravenous formulation. Cangrelor, a potent intravenous $\mathrm{P} 2 \mathrm{Y}_{12}$ platelet receptor inhibitor with a rapid onset of action and fast clearance from the body, is especially useful in this population. In addition, this drug's unique pharmacokinetic properties offer advantages over oral $\mathrm{P} 2 \mathrm{Y}_{12}$ receptor inhibitors given the high risk of bleeding in the early postoperative period (ie, ongoing chest tube drain, fresh wound, etc) and the inability to reverse the latter options.

\section{CONCLUSIONS}

Improvements in surgical techniques over the last several decades have resulted in treatment of increasingly complex cardiac diseases. Nonetheless, postoperative MI remains a common complication that is difficult to manage in the absence of strong evidence and guidelines. Clinical evaluation with a focused physical examination, ECG, and noninvasive imaging is warranted to decide on whether to proceed with coronary angiography or reoperation. Additional studies are needed to investigate the utility of new imaging technologies and high-sensitivity troponin assays on the diagnosis of post-CS MI.

\section{Conflict of Interest Statement}

Dr Dangas reports institutional research grants from Abbott Laboratories, AstraZeneca, Bayer, Boston Scientific, Medtronic, and Daiichi-Sankyo; consultant fees from Biosensors; and speaker honoraria from Chiesi. All other authors reported no conflicts of interest.

The Journal policy requires editors and reviewers to disclose conflicts of interest and to decline handling or reviewing manuscripts for which they may have a conflict of interest. The editors and reviewers of this article have no conflicts of interest.

\section{References}

1. Thielmann M, Sharma V, Al-Attar N, Bulluck H, Bisleri G, Bunge JJH, et al. ESC joint working groups on cardiovascular surgery and the cellular biology of the heart position paper: peri-operative myocardial injury and infarction in patients undergoing coronary artery bypass graft surgery. Eur Heart J. 2017;38:2392-407.

2. Thygesen K, Alpert JS, Jaffe AS, Chaitman BR, Bax JJ, Morrow DA, et al. Fourth universal definition of myocardial infarction (2018). J Am Coll Cardiol. 2018;72: 2231-64.

3. Whittaker A, Aboughdir M, Mahbub S, Ahmed A, Harky A. Myocardial protection in cardiac surgery: how limited are the options? A comprehensive literature review. Perfusion. 2021;36:338-51.

4. Alberti KGMM, Eckel RH, Grundy SM, Zimmet PZ, Cleeman J, Donato KA, et al. Harmonizing the metabolic syndrome: a joint interim statement of the International Diabetes Federation task force on epidemiology and prevention; National Heart, Lung, and Blood Institute; American Heart Association; World 
Heart Federation; International Atherosclerosis Society; and International Association for the Study of Obesity. Circulation. 2009;120:1640-5.

5. Lamy A, Devereaux PJ, Prabhakaran D, Taggart DP, Hu S, Paolasso E, et al. Offpump or on-pump coronary-artery bypass grafting at 30 days. $N$ Engl J Med. 2012;366:1489-97.

6. Puskas JD, Williams WH, Mahoney EM, Huber PR, Block PC, Duke PG, et al. Off-pump vs conventional coronary artery bypass grafting: early and 1-year graft patency, cost, and quality-of-life outcomes: a randomized trial. JAMA. 2004;291: 1841-9.

7. Coutinho GF, Leite F, Antunes MJ. Circumflex artery injury during mitral valve repair: not well known, perhaps not so infrequent-lessons learned from a 6-case experience. J Thorac Cardiovasc Surg. 2017;154:1613-20.

8. Caruso V, Sabry H, Birdi I. Dramatic resolution of an immediate postoperative distortion of the circumflex artery during mitral valve surgery. J Card Surg. 2020;35:1135-7.

9. Cabrol C, Pavie A, Gandjbakhch I, Villemot JP, Guiraudon G, Laughlin L, et al. Complete replacement of the ascending aorta with reimplantation of the coronary arteries: new surgical approach. J Thorac Cardiovasc Surg. 1981;81:309-15.

10. O'Connor E, Fraser J. The interpretation of perioperative lactate abnormalities in patients undergoing cardiac surgery. Anaesth Intensive Care. 2012;40:598-603.

11. Cubero-Gallego H, Lorenzo M, Heredia M, Gómez I, Tamayo E. Diagnosis of perioperative myocardial infarction after heart valve surgery with new cut-off point of high-sensitivity troponin $\mathrm{T}$ and new electrocardiogram or echocardiogram changes. J Thorac Cardiovasc Surg. 2017;154:895-903.

12. VARC-3 Writing Committee, Généreux P, Piazza N, Alu MC, Nazif T, Hahn RT, et al. Valve academic research consortium 3: updated endpoint definitions for aortic valve clinical research. Eur Heart J. 2021;42:1825-57.

13. Cerqueira MD, Weissman NJ, Dilsizian V, Jacobs AK, Kaul S, Laskey WK, et al. Standardized myocardial segmentation and nomenclature for tomographic imaging of the heart: a statement for healthcare professionals from the cardiac imaging committee of the council on clinical cardiology of the American Heart Association. Circulation. 2002;105:539-42.

14. Mehran R, Dangas GD, Weisbord SD. Contrast-associated acute kidney injury. $N$ Engl J Med. 2019;380:2146-55.

15. Alqahtani F, Ziada KM, Badhwar V, Sandhu G, Rihal CS, Alkhouli M. Incidence, predictors, and outcomes of in-hospital percutaneous coronary intervention following coronary artery bypass grafting. J Am Coll Cardiol. 2019;73:415-23.

16. Parasca CA, Head SJ, Milojevic M, Mack MJ, Serruys PW, Morice M-C, et al Incidence, characteristics, predictors, and outcomes of repeat revascularization after percutaneous coronary intervention and coronary artery bypass grafting: the SYNTAX trial at 5 years. JACC Cardiovasc Interv. 2016;9:2493-507.

17. Levine GN, Bates ER, Blankenship JC, Bailey SR, Bittl JA, Cercek B, et al. 2011 ACCF/AHA/SCAI guideline for percutaneous coronary intervention: a report of the American College of Cardiology Foundation/American Heart Association task force on practice guidelines and the Society for Cardiovascular Angiography and Interventions. J Am Coll Cardiol. 2011;58:e44-122.

18. Vuylsteke A, Pagel C, Gerrard C, Reddy B, Nashef S, Aldam P, et al. The Papworth bleeding risk score: a stratification scheme for identifying cardiac surgery patients at risk of excessive early postoperative bleeding. Eur J Cardiothorac Surg. 2011;39:924-30.

19. Chaudhry R, Zaki J, Wegner R, Pednekar G, Tse A, Sheinbaum R, et al. Gastrointestinal complications after cardiac surgery: a nationwide population-based analysis of morbidity and mortality predictors. J Cardiothorac Vasc Anesth. 2017;31:1268-74.

Key Words: cardiac surgery, myocardial infarction, postoperative complications 